new lead-covered contact " perspex" shells for protection of the eyes in short-distance low-voltage X-ray treatment are described. The advantages of this form of X-ray therapy and the results obtained in the treatment of tumours of the lids and canthi during the last four years at the Royal Cancer Hospital (Free) are discussed.

Acknowledgment.-I am greatly indebted to Mr. E. A. Plaice and Mr. W. Hoad of Messrs. Clement Clarke who have assisted me throughout in the preparation of the eye shields. They have been entirely responsible for their construction and I am most grateful to them for furnishing me with some notes on this subject which have been included in this paper. I am also indebted to Mr. J. H. Wood the pharmacist at the Royal Cancer Hospital who carried out the tests on "perspex" with various antiseptics.

\title{
REFERENCES
}

1. Desjardins, A. U.-Amer. Jl. Roentgenol., Vol. XXVI, pp. 639-679, 789-819, 923-942, 1931.

2. ClAPP, C. A.-Amer. Jl. Ophthal., Vol. XV, pp. 1039-1044, 1932.

3. Martin, P.-Brit. Med. Jl., Vol. I, pp. 651-654, 1937.

4. Chaoul, H., and Adam, A.-Strahlentherapie, Vol. XLVIII, pp. 31-50, 1933.

5. Flood, P. A., and Smithers, D. W.-Brit. Jl. Radiol., Vol. XII, pp. 462$485,1939$.

6. Regaud, C.. Coutard, H., Monod, O, and RiChard, G.-Ann. d'Ocul., Vol. CLXIII, pp. 1-30, 1926.

7. WölfFliN, E.-Strahlentherapie, Vol. XLIV, pp. 800-801, 1932.

8. Cutler, M., Jaffe, H. L. and Grossman, A.-Amer. Jl. Ophthal., Vol. XXI, pp. 747-754, 1938.

9. Watson, W. L. and Wuester, W.-Amer. Jl. Ophthal., Vol. XXI, pp. 261263, 1938.

10. Chaoul, H.-Strahlentherapie, Vol. LVIII, pp. 611-613, 1937.

11. Driver, J. R. and Cole, H. N.-Amer. Jl. Roentgenol., Vol. XLI, pp. 616$624,1939$.

\section{POST-CATARACT HYPHAEMA}

BY

A. Seymour Philps, F.R.C.S.

LONDON

Post-Cataract hyphaema has long been one of the bugbears of ophthalmic surgery, for though it does not often affect the ultimatevisual result, it prolongs the patient's stay in hospital sometimes. for several weeks. In an endeavour to ascertain the origin and fate of the blood in these patients I have collected and recorded every such hyphaema that occurred in the wards of two London Hospitals during the years 1937 and the greater part of 1938 . 
Daily visits were paid to these hospitals and thus none was missed and small changes in those already recorded were noted. In all 49 cases were collected, and Table I gives further details of these patients.

\section{TABLE I}

To show the total number of hyphaemata occurring in 374 consecutive cataract extractions.

\begin{tabular}{|c|c|c|c|}
\hline Type of operation & $\begin{array}{c}\text { Total } \\
\text { number } \\
\text { performed }\end{array}$ & $\begin{array}{c}\text { Number } \\
\text { of } \\
\text { hyphaemata }\end{array}$ & $\begin{array}{c}\text { Percentage } \\
\text { of } \\
\text { total }\end{array}$ \\
\hline Extraction with iridectomy & 218 & 29 & $13 \cdot 3$ \\
\hline Extraction without iridectomy & 119 & 15 & $12 \cdot 6$ \\
\hline $\begin{array}{c}\text { Extraction after preliminary } \\
\text { iridectomy }\end{array}$ & 37 & 5 & $13 \cdot 5$ \\
\hline TOTAL & 374 & 49 & $13 \cdot 13$ \\
\hline
\end{tabular}

It will immediately be noticed that the figures in the last column are remarkably consistent, leading one to suppose that whatever the origin of the blood it is unaffected by the type of operation performed. If, as has been frequently stated, the blood comes from the iris one would surely have expected a higher difference than 0.7 per cent. between those cases where it was cut and those where it was not.

It soon became apparent that these hyphaemata could be divided into three groups.

1. Those occurring at the time of operation, probably from the conjunctival flap. It has often been noticed that these hyphaemata absorb very rapidly and unless they are very large will have disappeared by the time the first dressing is done 48 hours later. In this survey I have included only those cases which persisted at the first dressing or occurred at a subsequent date and therefore very few of this type are mentioned in this paper.

2. Those occurring for the first time several weeks after the operation concurrently with an attack of iritis. They are prone to recur at frequent intervals and have a different origin from the next group.

3. Forty-two out of forty-nine cases fell into this group. They have the following characteristics:table.

$a$ They are not present when the patient leaves the operating 
$b$ They occur between the second and the tenth days, and almost invariably between the second and the sixth.

$c$ It is only very rarely that more than one single haemorrhage occurs, and the eye is usually free from blood in $2-3$ weeks.

I have no doubt that those cases classed in Group 2 are inflammatory in nature antl arise from the iris. In the remainder of this paper I am referring to group 3 unless otherwise stated.

History of occurrence.-For the most part these patients had their first dressing 48 hours after the operation, and thereafter daily unless the eye became painful and an inspection was indicated. When they were recorded an accurate history of onset in the patient's own words was also taken down. When this had been done the following facts emerged.

Ten patients gave a definite history of physical violence to the eye. In most cases this consisted of knocking the eye with the hand-usually on first waking up. This would be followed by a complaint of pain in the eye and on inspection a hyphaema was found.

Fifteen patients volunteered some such information as "I went back with rather a bump and after that my eye was painful." Or "I had an attack of sneezing, doctor." Or "I dreamt the cat was after the canary and I woke up with a start and my eye was painful."

TABLE II

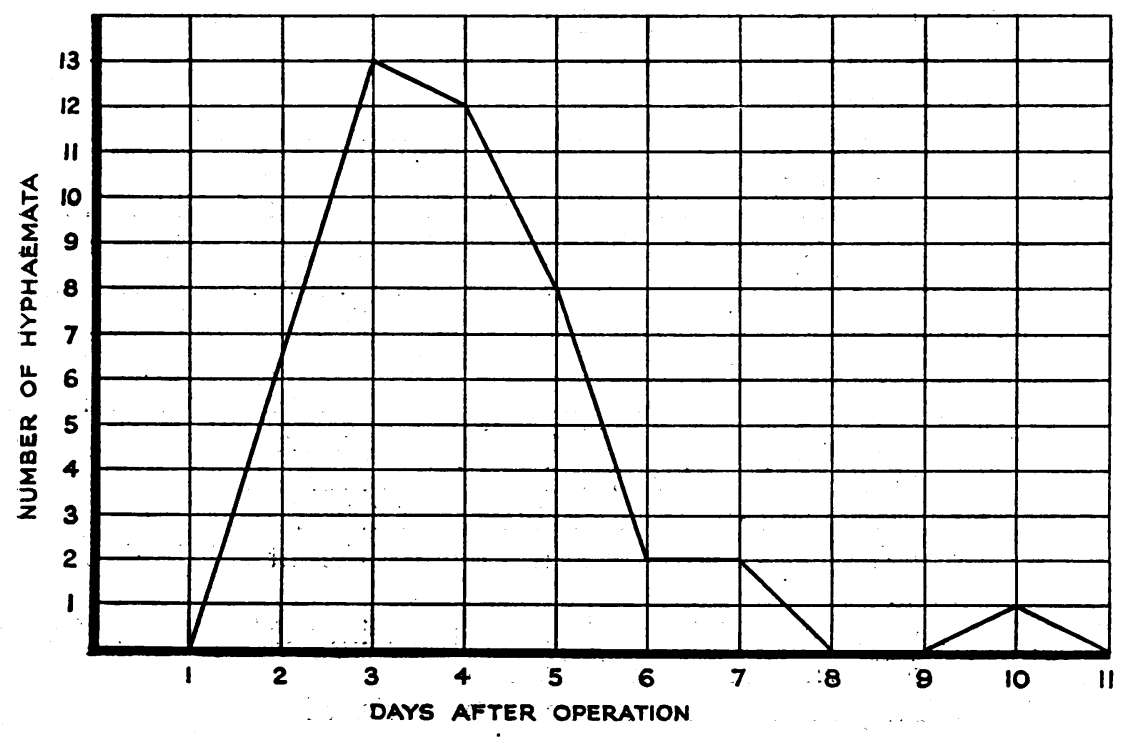


In the remaining 17 patients the blood was found at a routine dressing and no complaint of pain was forthcoming from the patient unless perhaps following a leading question.

So that in spite of the fact that the patient or the nursing staff is often blamed for the trouble, in less than a quarter of the cases

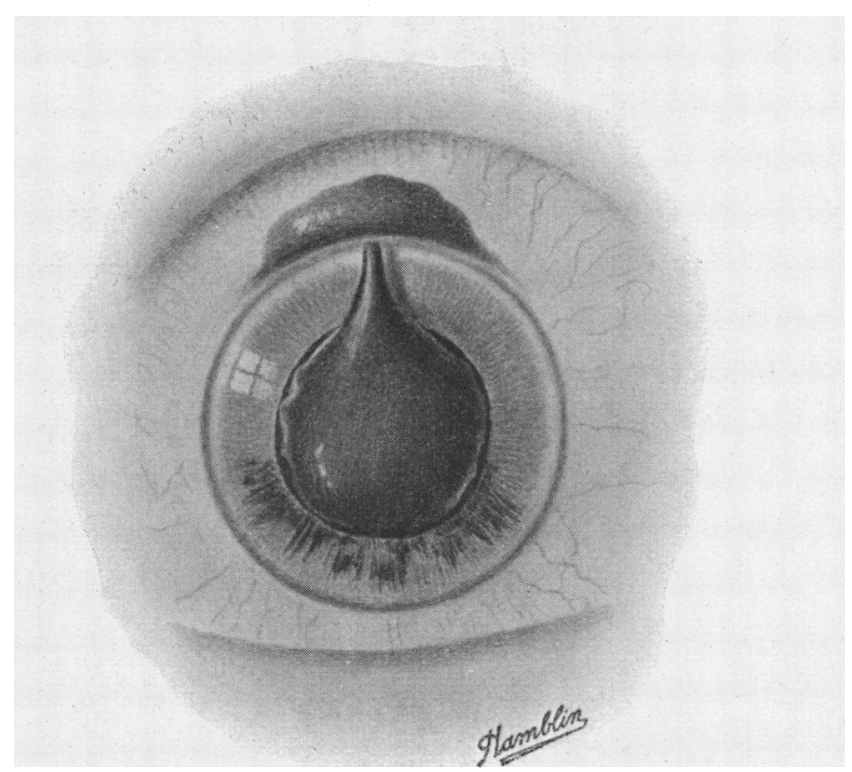

FIG. 1.

To show a hyphaema coming from the section and causing some re-opening of the wound and subconjunctival extravasation. The clot appears to fit the pupil exactly, but this was not so when it first appeared. The blood covering the iris has almost all been absorbed. At a later stage the pedicle of the clot will disappear, and the eye will then present the familiar picture of a single disc of blood occupying the pupil.

was there any evidence of a knock which might perhaps have been prevented by wearing a cage or tying the patient's hands.

Time of occurrence.- No case occurred before the second day, or after the tenth. The average for all cases was 3.7 days and the accompanying graph shows when they took place.

Appearance of hyphaema. - The blood is venous in colour and tends to become darker the longer it remains in the anterior chamber. There are three main types.

1. It may completely fill the anterior chamber and cause some re-opening of the wound and extravasation beneath the conjunctival flap. See Fig. 1.

2. There may be a clot attached to the section above, and a pool of blood lying at the bottom of the anterior chamber. See Fig. 2. 


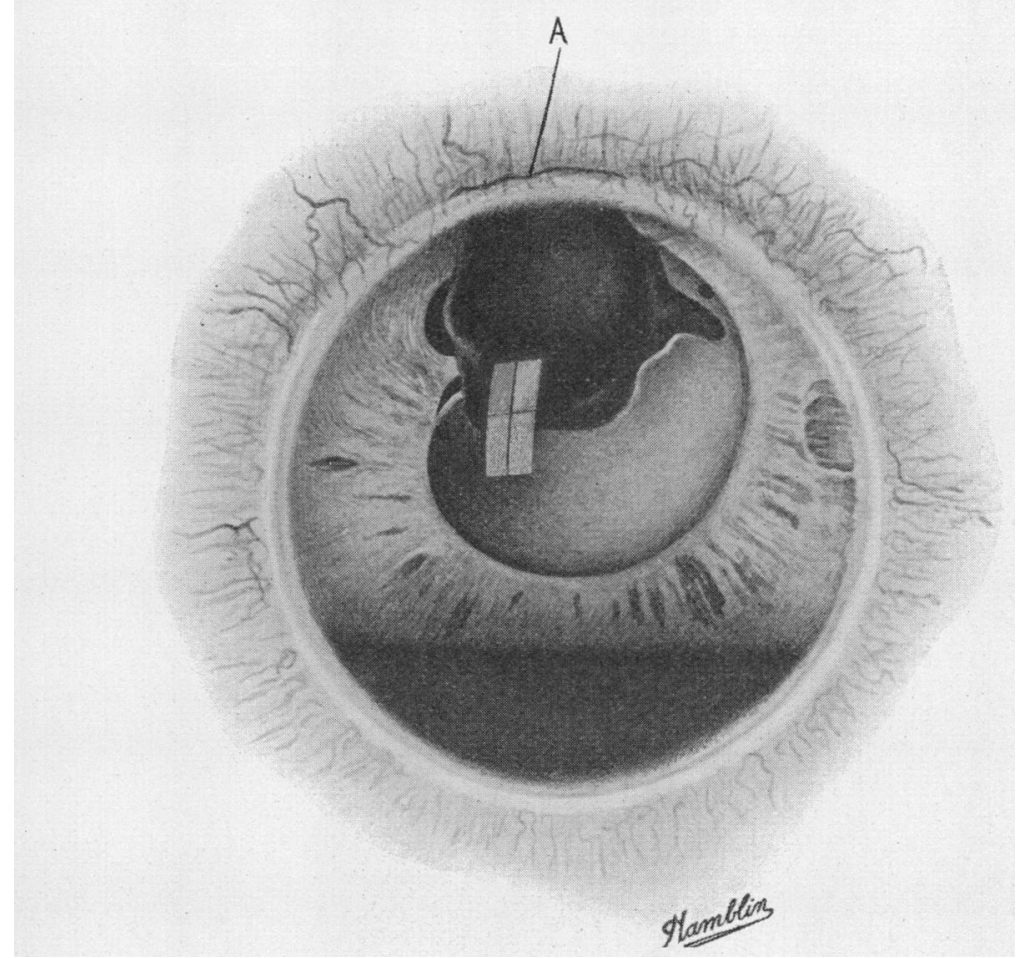

FIG. 2.

To show a clot attached to the section above; and a pool of cells below. Note also the slight separation of the wound edges at $A$. The preliminary iridectomy had been performed some months previously.

3. There may be merely a pool of blood at the bottom of the A.C. with no clear indication whence it came, though a careful search with a binocular loupe will reveal a small clot attaching to the section in a surprising number of cases.

Subsequent History of Hyphaema.-Once the haemorrhage had occurred these patients did not complain of any more pain. A second haemorrhage was a great rarity, and in only one case was I sure that this had happened. Several interesting facts were noted while watching the blood absorb. Any clot present slowly diminished in size, and the free cells in the A.C. gained by almost as much as the clot had lost. Thus-
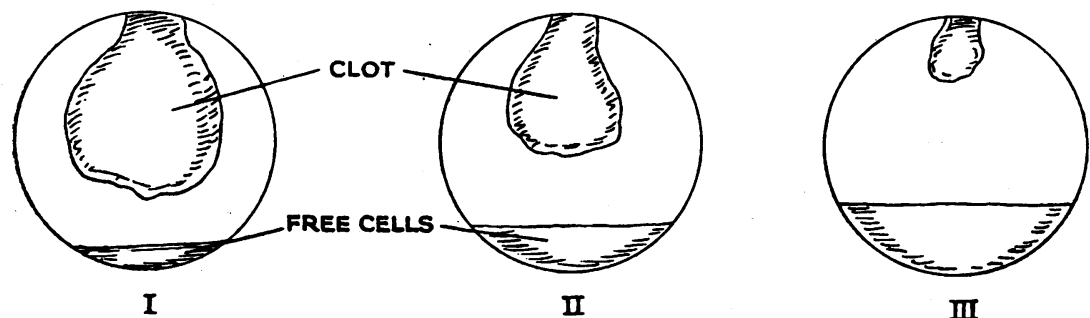

III 
Slowly the free cells disappeared, until, in $2 \frac{1}{2}$ to 3 weeks there was none left. However, it was always found that where an iris coloboma existed a thin layer of red cells might be found at this spot attached to the lens capsule long after it had disappeared elsewhere, and the same was true of the pupillary opening. These observations have been made before and have rightly been held to point to the iris as the important structure in blood absorption.

With regard to the disappearance of clots in the anterior chamber, I believe that the fibrin of the clot is dissolved by the aqueous humour and the cells are thus set free to be absorbed into the crypts of the iris, the aqueous having no direct action on them. This is not unlikely when one remembers that aqueous dissolves lens globulin, and therefore why not serum globulin? It is not impossible that this constant action of the aqueous on fibrin is responsible for the absence of scarring of the iris after it has been cut, and for the fact that fibrosis in the anterior chamber after trauma or inflammation is always reduced to a minimum.

I do not know how long it is possible for cells to remain intact in the A.C., but I have washed them out and examined them after they have been present for seven weeks and have found them intact. In this connection it is interesting to note those case histories mentioned later where blood entangled in the vitreous has remained for months and even years without any marked change taking place.

Absorption of hyphaemata.

TABLE III

\begin{tabular}{|c|c|c|}
\hline Type of operation & & $\begin{array}{l}\text { Average number of } \\
\text { days to absorb }\end{array}$ \\
\hline Extraction with iridectomy & - & $18 \cdot 6$ \\
\hline Extraction without iridectomy & - & $18 \cdot 3$ \\
\hline After preliminary iridectomy - & - & $18 \cdot 5$ \\
\hline Average of all types of operation & - & $18 \cdot 46$ \\
\hline
\end{tabular}

These times are for the disappearance of all clot and free blood cells, but do not include blood in the pupil or in an iris coloboma which may remain for many weeks.

There are certain conditions which appear to retard absorption-

1. Tension of the eye. It is unusual for blood in the A.C. to cause a rise of tension, but where it does so or where the tension is raised for some other reason, absorption of blood seems to cease entirely. 
2. Failure of the A.C. to reform was the cause of delay in one case.

3. Old iritis such as may be found in cases of complicated cataract.

4. Vitreous prolapse through the pupil. I have now collected four cases of this interesting condition associated with hyphaema. Three occurred after cataract extraction and one after needling. The former were all similar and showed streaks of blood entangled in the vitreous which had prolapsed through the pupil. Absorption was delayed for some months. The latter case has the longest history and I have thought it worth recording.

J. H., aged 79 years; had a cataract extraction without iridectomy on March 9, 1935, and a needling a few weeks later. From that time onwards it was noticed that there was a speck of blood in the A.C. which did not alter in appearance. That was 3 years ago, and it was still there in September, 1938. Slit-lamp examination showed that there was a vitreous prolapse through the pupil, and on the summit of this prolapse a speck of blood. It was waving about in the A.C. and did not anywhere come into contact with the iris or any other structure. It was venous in colour and appeared to be stuck to the surface of the vitreous. For this blood to have remained so long freely washed over by the aqueous without effect seems to show that the aqueous has no action on whole red cells. Figure 3 is a slit-lamp painting of this patient's eye. On writing to her to come up for another examination quite recently, I found that she had been admitted to hospital on account of pain in the eye due to increased tension and that the eye had been removed.

5 . I have on several occasions been told that a hyphaema had " absorbed yesterday, but there is a small one present again today." In many of these patients it is possible to produce a hyphaema at will by standing the patient up. When lying down it is possible for a small amount of blood to disappear from view by entering crypts of the iris, but if the patient then stands up the blood exudes from the crypts and collects at the bottom of the A.C. This appearance may simulate an iris haemorrhage.

Origin of the blood.-There are three sources from which it is possible for blood to enter the A.C., (a) the conjunctival flap, $(b)$ the healing section and $(c)$ the iris and ciliary body. Clearly it can only come from the conjunctiva during the operation, from the section while it is healing, but from the iris and ciliary body at any time.

I have assumed that those haemorrhages that occur at operation are mostly conjunctival in origin, while those that occur more than three weeks after operation are from the iris, and thus the real point at issue is the source of the 42 cases that arose between the 


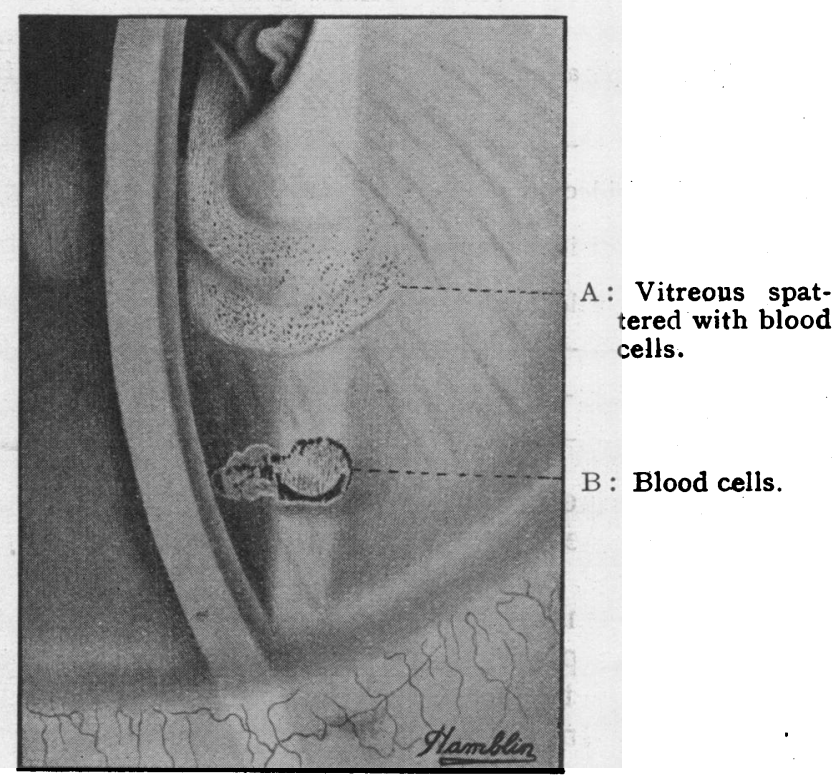

FIG. 3.

Slit-lamp drawing of an eye in which blood entangled in vitreous humour has been present in the anterior chamber for $2 \frac{1}{2}$ years. Although it cannot be made out in this drawing, slit-lamp examination made it quite certain that the clot of blood was attached to the cloud of vitreous which can be seen above it.

second and the tenth days. Since it is only very rarely that a hyphaema is seen in the act of formation it follows that the source of the blood must be a matter of deduction from circumstantial evidence.

In only one case have I seen a hyphaema occur. The patient squeezed her lids during an examination and I was able to see the blood trickling down from the section.

Many patients showed a large clot attached to the section as drawn in Figs. 1 and 2, and many more a much smaller clot only apparent on examination with a loupe. Finally there remained 11 patients in whom I found merely a pool of blood at the bottom of the A.C. with no clear indication whence it came. The behaviour and appearance of these last was in every way similar to those known to come from the section and I believe that they have the same source. Therefore in 49 patients in whom a hyphaema persisted at the first dressing or appeared subsequently we find the following- 
TABLE IV.

\begin{tabular}{c|c|c|c|c}
\hline Type of operation & $\begin{array}{c}\text { Number } \\
\text { of } \\
\text { hyphaemata }\end{array}$ & $\begin{array}{c}\text { Number } \\
\text { from con- } \\
\text { junctival } \\
\text { vessels }\end{array}$ & $\begin{array}{c}\text { Number } \\
\text { from } \\
\text { iris }\end{array}$ & $\begin{array}{c}\text { Number } \\
\text { from } \\
\text { section }\end{array}$ \\
\hline Extraction with iridectomy - & 29 & 2 & 2 & 25 \\
Extraction without iridectomy - & 15 & 1 & 1 & 13 \\
After preliminary iridectomy - & 5 & 0 & 1 & 4 \\
\hline Totals - - & 49 & 3 & 4 & 42 \\
\hline
\end{tabular}

Finally, if one takes the 42 patients in Group 3, i.e., those occurring between the second and tenth day, 41 arose from the section, and one, on the tenth day, from the iris.

I believe the manner in which it occurs is as follows. Repair of a section takes place by means of blood vessels growing down from the conjunctival and episcleral vessels. Owing to the tension of the eye a cataract section always gapes to some extent, and this gap is made good by young vascular tissue. Should the patient now squeeze his lids, this will cause deformation of the eyeball and separation of the wound edges and thus rupture of the young blood vessels uniting them. When this happens the vessel bleeds, usually in the line of least resistance into the A.C., but occasionally subconjunctivally as well.

Proof that there are young blood vessels in the wound on the third day is forthcoming from some work by Mr. Treacher Collins in 1914. He was able to show, at a meeting of the Ophthalmological Society, microscopical evidence of these vessels in human eyes which had been removed shortly after operation. At this same meeting the matter was put in a nutshell by Mr. Claud Worth when he said " he thought the haemorrhage must come from the vessels which $\mathrm{Mr}$. Treacher Collins had demonstrated growing down from the conjunctival flap. He thought it must be produced by some movement on the part of the patient, not necessarily a blow, but some strain such as squeezing the lids which causes a partial opening of the wound and a rupture of some of the vessels at a stage when they had grown sufficiently to bleed but could not resist a little violence."

It seems to me there is another test that one can apply to these patients. The wound can only bleed if there are vessels repairing it. If the wound is entirely corneal it does not heal by vascularisation, and thus a cataract extraction through an entirely corneal wound should not bleed on the third day. I have made a practice 
of recording the site of the section in each case and have not found any bleeding in these patients. If the section is at the limbus, or only just to the corneal side of it, this argument does not apply, as these eyes frequently heal by vessels growing in from the episclera.

Corneo-scleral sutures.-After the cases in this paper had been collected corneo-scleral sutures were introduced at one of the hospitals where I was working. For a period of six months this stitch was used on every cataract extraction by one of the surgeons, and during this time no single case of post-cataract hyphaema occurred in his cases. The stitch has now been used on over 120 consecutive cases without a haemorrhage.

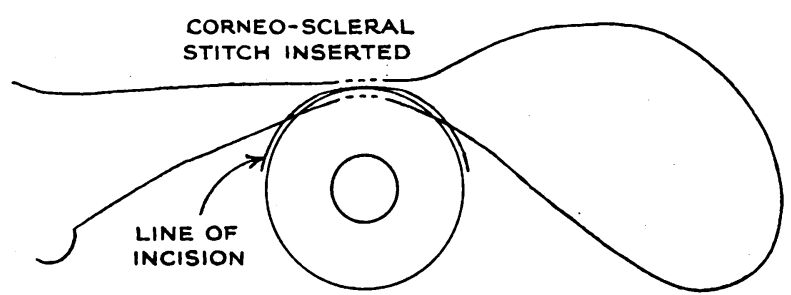

I

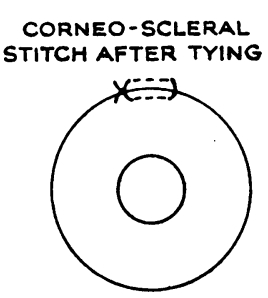

II

I believe the explanation to be that this suture prevents the wound edges from separating however much the eyeball is deformed. If it is argued that these patients had no haemorrhage because, from the nature of the stitch, the section must be limbal or corneal, I can state that while this may be so in some cases there are many more in which the wound heals by vascularisation. I should not have expected such a complete freedom from haemorrhage as has, in fact, occurred in patients in which this suture is used, as there are certainly a small minority of cases in which the blood comes from the iris. It is interesting to note that " bridge" extractions are by no means free from hyphaemata, and the same is true of those patients where a sclero-conjunctival suture is used.

Relation of high blood pressure to hyphaema.-In fifty consecutive extractions I took the patient's blood pressure, and did not find that it had any relation to the incidence of hyphaema formation.

Relation of diabetes to hyphaema.-In the 49 cases of postcataract hyphaema there were five diabetics. This gives a percentage of just over 10 , which is approximately the ratio of diabetics to non-diabetics in all cataract extractions. It would seem therefore that diabetes has no direct relationship to hyphaema. However, of the four cases that bled from the iris, three were diabetics. One may therefore conclude that diabetes 
only contributes to hyphaema formation in that it increases the likelihood of iritis, and therefore of hyphaema from this cause.

Literature.-An extensive literature has accumulated on the subject of post-cataract hyphaema devoted to the two main problems of this complication, $(a)$ the percentage of patients in which it occurs, and (b) the source of the blood.

With regard to $(a)$ the figure varies from 1.25 per cent. (Devereux Marshall 1895) to 18.7 per cent. (Carle 1932), while the average for all available figures is 7.9 per cent. On reading the accounts of these authors one reason for these widely differing figures becomes evident. The higher figures are the result of personal observation of the cases by the surgeon, and the lower occur where the figures were compiled from hospital records at the end of the year.

The accompanying table is taken from Vail's article on the subject, in which he gives his own percentage as $5 \cdot 29$, and his belief that they come from the section.

Statistics of previous writers.

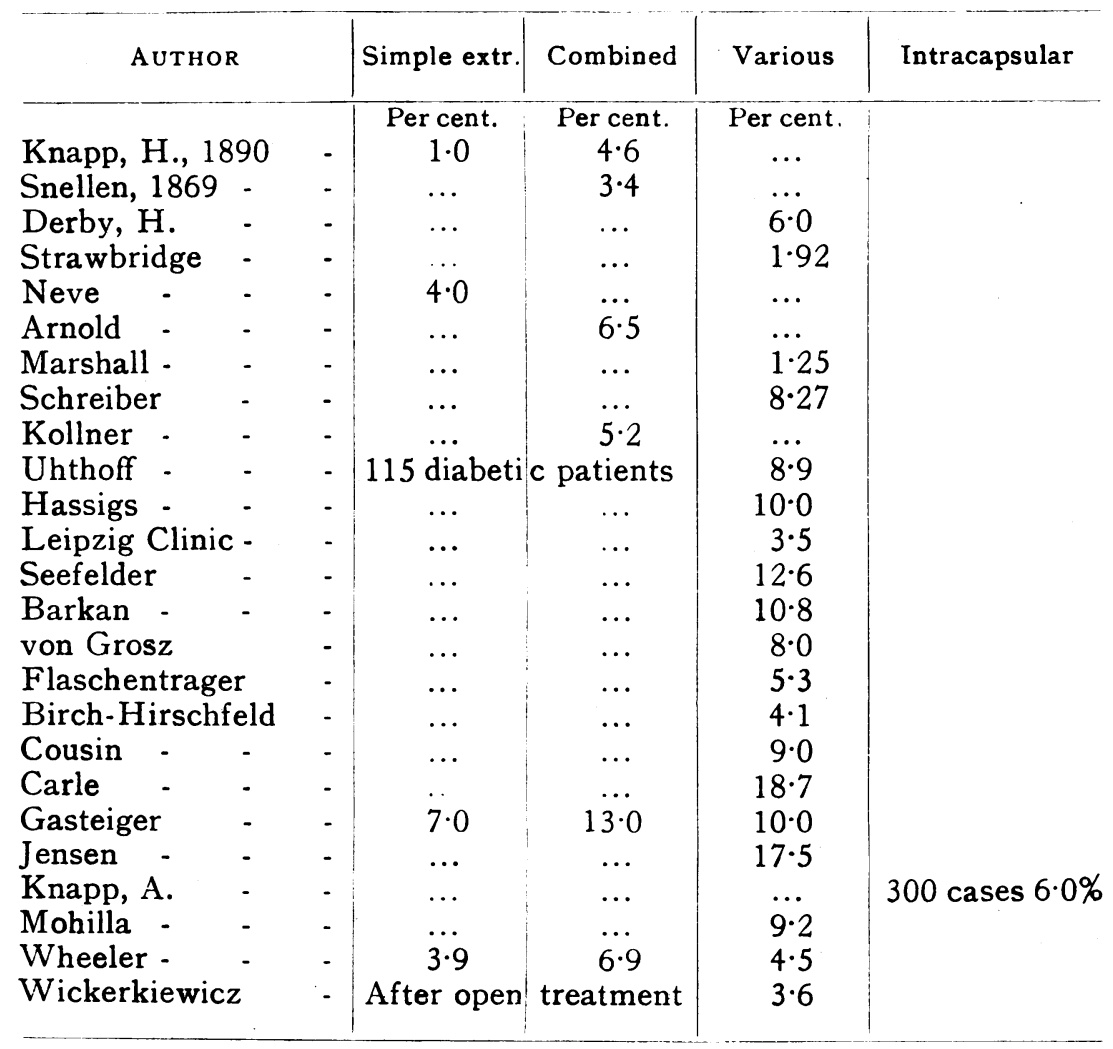




\section{Post-Cataract HyphaEma}

Regarding (b), the source of the blood, opinion has lately been changing, and while most of the older writers thought that it came from the iris many of the younger ones believe that it comes from the section. The matter is clearly one which it is impossible to decide by examining hospital notes, and I think that when the effect of using corneo-scleral sutures becomes more widely known opinion on this matter will become more unanimous than it is at present.

Fate of blood in the anterior chamber.-The only certain evidence of the route by which blood leaves the A.C. is obtained by experimental methods, and I have injected blood withdrawn trom rabbit's ears into the A.C. of the same animal with a view

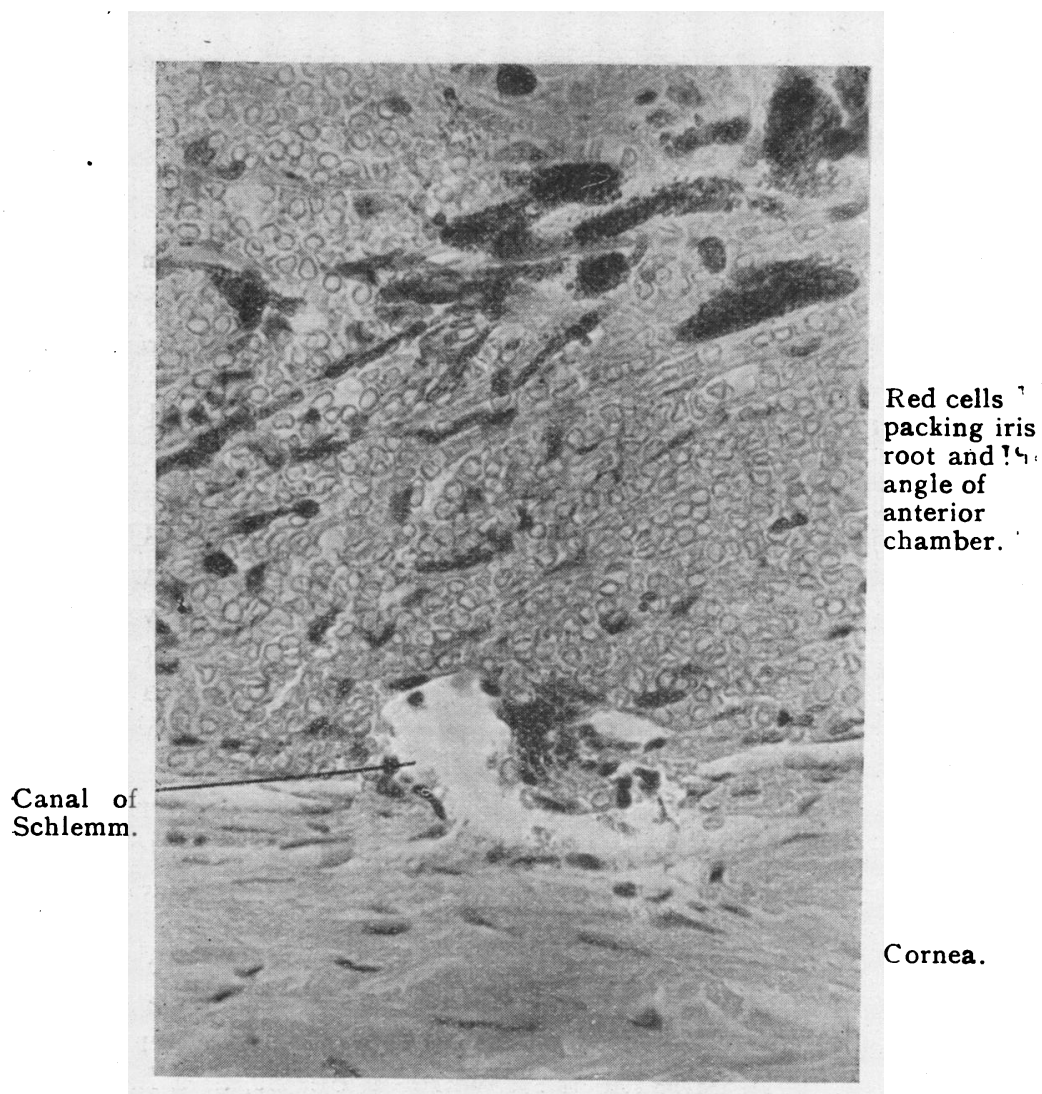

Microphotograph No. 1. 650 diameter.

To show the canal of Schlemm in a rabbit's eye. The anterior chamber and iris are packed with cells, but the canal of Schlemm remains comparatively empty. This eye was removed three days after the injection of the blood. 


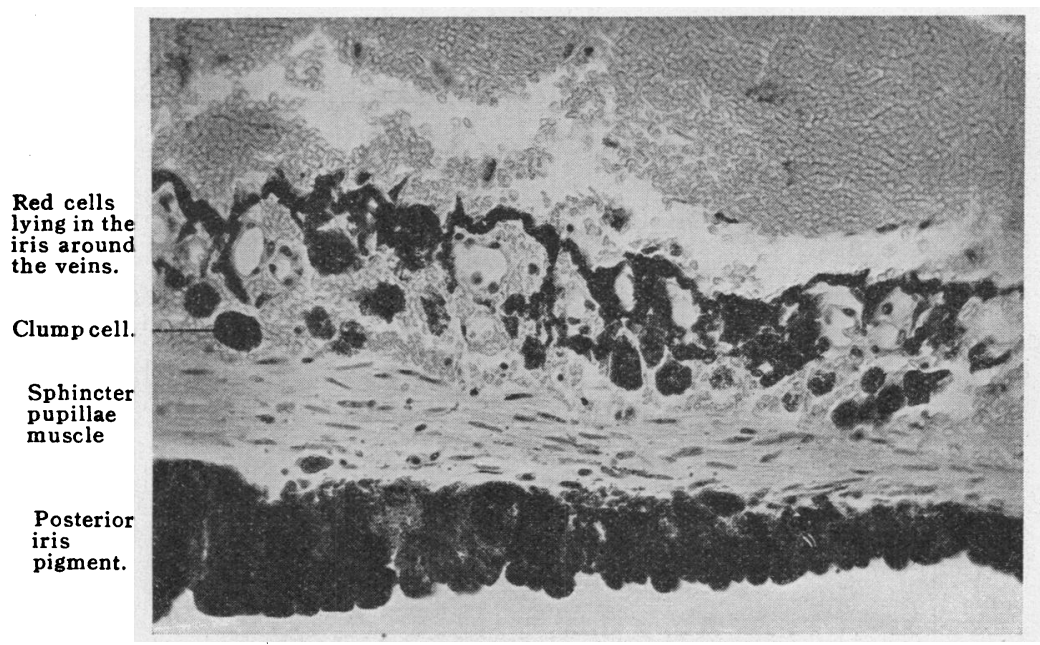

Red cells in the anterior

Microphotograph No. 2. 350 diameter.

Removed seven days after injection. A transverse section of the iris just below the pupil, showing red cells entering the anterior surface of the iris, and lying around the iris veins. A number of "clump cells" have migrated towards the area.

to obtaining such evidence. Nevertheless, it is possible to make many deductions from clinical evidence before going on to this.

It has been remarked before that blood in the pupil or in an iris coloboma remains when blood elsewhere in the A.C. has been absorbed. In other words, blood has to be in contact with the iris before it can disappear. This is a fundamental observation.

Secondly, the aqueous humour appears to have no action on isolated cells, proof of this coming from the fact that a hyphaema can be washed out of the A.C. many weeks after it has occurred and the cells found to be microscopically intact.

Thirdly, clots of blood can be seen to dissolve in the A.C. although the total amount of blood present may remain the same. The reason why it is thought that the aqueous can dissolve the fibrin from the clot has been given already.

Experimentally I have excised rabbit's eyes some days after injecting blood into the A.C. By this means it can be shown that once the cells have been freed from the clot they enter the crypts of the iris, travel inside the iris towards the root, and having done this enter the anterior ciliary veins. They do not enter the canal of Schlemm, at any rate in great numbers, and there is no evidence of their being phagocytosed by leucocytes. The two microphotographs will show some of these points. 


\section{Summary}

1. In 374 consecutive extractions there occurred 49 hyphaemata, giving a percentage of $13 \cdot 13$.

2 . Of these, 42 came from the section ( 85 per cent.), and the remainder from the iris and conjunctival flap.

3 . In those that came from the section the average day of occurrence was 3.7 days after the operation, and they took 18.4 days to absorb.

4. The type of operation has no influence on the incidence of hyphaema.

5. No general condition such as diabetes or hyperpiesis has any influence in their occurrence.

6. It is due to local trauma such as squeezing the lids, which causes separation of the wound edges and rupture of the young vessels in the section.

7. They can be prevented by the use of a corneo-scleral stitch.

8. Several factors are enumerated which cause delay in absorption of the blood.

9. The literature is reviewed, and though there is some difference of opinion, most of the younger authors think that they come from the section.

10. The aqueous humour has no action on red cells, but can dissolve fibrin from the clot.

11. The cells are absorbed by the iris, and do not enter the canal of Schlemm.

\section{DISLOCATION OF THE LENSES, WITH OTHER CONGENITAL DEFECTS: SECONDARY GLAUCOMA}

BY

\section{N. BISHOP HARMAN and ROBERT BUXTON \\ LONDON \\ WESTON-SUPER-MARE}

THE subject of these defects is an only child of normal parents. He was noticed to be short-sighted at the age of 3 years. Glasses were ordered by an ophthalmic surgeon at the age of 5 years : right and left $-18 \mathrm{D}$. sphere. At the age of 7 years, he was seen by Mr. R. C. Elmslie on account of his physique. "He had metatarsus varus of severe degree in both feet. This was practically a very mild form of congenital talipes in which the anterior part of the foot only was inverted. His physique was very poor and his posture bad."

N. B. H. saw him in 1928 , and ascertained the above facts. 